\title{
Microstructure evolution-based design of thermal post- treatments for EBM-built Alloy 718
}

\author{
Sneha Goel ${ }^{1, *}\left(\mathbb{D}\right.$, Enrico Zaninelli ${ }^{2}$, Johannes Gårdstam ${ }^{3}$, Uta Klement ${ }^{4}$, and \\ Shrikant Joshi ${ }^{1}$ \\ ${ }^{1}$ Department of Engineering Science, University West, 46186 Trollhättan, Sweden \\ ${ }^{2}$ Department of Engineering Enzo Ferrari, University of Modena and Reggio Emilia, 41100 Modena, Italy \\ ${ }^{3}$ Quintus Technologies AB, 72166 Västerås, Sweden \\ ${ }^{4}$ Department of Industrial and Material Science, Chalmers University of Technology, 41296 Gothenburg, Sweden
}

Received: 7 September 2020

Accepted: 17 November 2020

Published online:

10 December 2020

(C) The Author(s) 2020

\begin{abstract}
Alloy 718 samples were fabricated by electron beam melting (EBM) additive manufacturing process. The work focused on systematic investigation of response of the material to various thermal post-treatments, involving hot isostatic pressing (HIPing), solution treatment (ST) and two-step aging, to tailor post-treatment procedure for EBM-built Alloy 718. Results showed that HIPing at lowered temperature can be used for attaining desired defect closure while preserving grain size. Subjecting the material to ST, with or without prior HIPing, mainly caused precipitation of $\delta$ phase at the grain boundaries with prior HIPing decreasing the extent of $\delta$ phase precipitation. Moreover, results suggest that the utility of ST, with prior HIPing, could be dictated by the need to achieve a certain $\delta$ phase content, as the typically targeted homogenization after ST had already been achieved through HIPing. Detailed investigation of microstructural evolution during subsequent aging with and without prior HIPing showed that a significantly shortened aging treatment (' $4+1^{\prime} \mathrm{h}$ ), compared to the 'standard' long treatment $\left(' 8+8^{\prime} \mathrm{h}\right)$ traditionally developed for conventionally produced Alloy 718 , might be realizable. These results can have significant techno-economic implications in designing tailored post-treatments for EBM-built Alloy 718.
\end{abstract}

Handling Editor: Sophie Primig.

Address correspondence to E-mail: sneha.goel@hv.se 


\section{GRAPHICAL ABSTRACT}

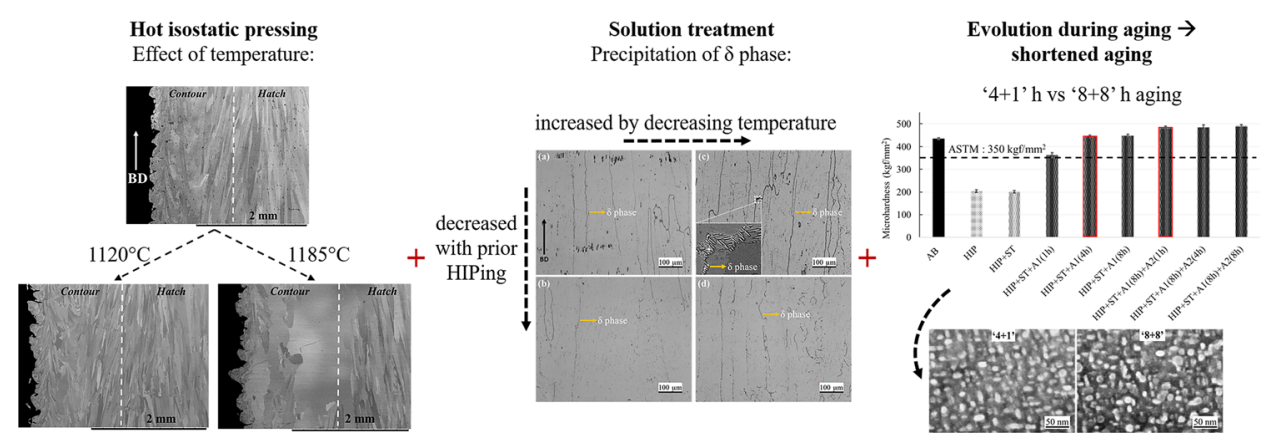

\section{Introduction}

Additive manufacturing (AM) through electron beam melting (EBM) powder bed fusion technique has gained growing interest for production of difficult-tomachine materials. One such material is Alloy 718, which is a Ni-Fe-based precipitation strengthened superalloy extensively used in off-shore, aerospace and energy sectors [1, 2]. Although Alloy 718 produced by EBM has been studied for several aspects, such as microstructure, mechanical behavior, residual stress, etc. $[3,4]$, relatively less attention has been paid on the effect of thermal post-treatments.

EBM-built Alloy 718 is typically subjected to thermal post-treatments to enhance the mechanical integrity. Thermal post-treatments typically involving hot isostatic pressing (HIPing) and heat treatments have been developed to reduce defects attributable to gas porosity, shrinkage porosity and lack of fusion, promote desired phase precipitation, etc., to ultimately improve the performance of Alloy 718 to meet the requirements of the service conditions [5-7]. Before stating the microstructure and mechanical behavior of EBM Alloy 718 it should be mentioned that majority of the reported characteristics of the EBM Alloy 718 correspond to the hatch region of the material. The hatch region comprises the bulk of the material which is surrounded by a 'border' known as contour region $[8,9]$.

Balachandramurthi et al. [8] have shown improved fatigue life of EBM Alloy 718 subjected to HIPing and heat treatment (comprising solution treatment (ST) and aging), with machined surface. The authors also noted much lower fatigue life when only heat treatment was employed. The improvement in fatigue life after posttreatment involving HIPing was attributed to mitigation of shrinkage porosities and lack-of-fusion defects through HIPing, whereas heat treatment had no evident effect on the defects. Thus the remnant defects, in case of latter, reduced crack initiation and propagation resistance in the material, as the defects are associated with accelerating local crack growth rate, thus causing reduced fatigue life of the material [8]. For similar reasons, the authors also reported increased monotonic tensile ductility after employing HIPing and heat treatment compared to the heat-treated case without prior HIPing. Barring differences in fatigue life and tensile ductility, the yield and ultimate tensile strength after heat treatment was similar irrespective of whether or not the material was subjected to prior HIPing [8]. These strength values were significantly higher than in the as-built condition as well as higher than the typical values for cast Alloy 718 and approached close to the properties of wrought material. Kirka et al. [10] have also observed improvement in tensile properties after subjecting the EBM Alloy 718 material to post-treatment involving HIPing and heat treatment. Moreover, the noted gradient in strength and ductility in the as-built condition was removed after the post-treatment. Creep properties of HIPed and heat-treated EBM Alloy 718 have been found to be comparable to the wrought material [11]. 
However, all the above-mentioned studies have employed HIPing at high temperature, i.e., $1200{ }^{\circ} \mathrm{C}$ which has been associated with concerns related to grain growth due to the high temperature [12-14]. Grain coarsening at higher HIPing temperatures has been shown to cause reduction in yield strength of Alloy 718 produced through powder compaction [15]. There have been very limited reported efforts on tailoring the HIPing parameters for EBM Alloy 718. Use of HIPing at lower temperatures $\left(1120^{\circ} \mathrm{C}, 2 \mathrm{~h}\right.$, $100 \mathrm{MPa} ; 800{ }^{\circ} \mathrm{C}, 2 \mathrm{~h}, 200 \mathrm{MPa}$ ) has been carried out to inhibit grain growth; however, the defects were not fully closed [16]. In the case of laser powder bed fusion (LPBF) Alloy 718, Tillmann et al. [17] have investigated reasonably wide variation in pressure and temperature during HIPing mainly with regard to densification. However, as noted above, in addition to densification, grain growth during HIPing is also an important concern to be investigated while tailoring HIPing conditions.

The HIPing treatment is typically followed by ST and two-step aging. Deng et al. [18] have studied effect of variation in ST temperature on the resulting EBM Alloy 718 microstructure, however without prior HIPing. Solution treatment at $930{ }^{\circ} \mathrm{C}$ and $980{ }^{\circ} \mathrm{C}$ resulted in populous precipitation of $\delta$ phase at the grain boundaries, while ST at $1080{ }^{\circ} \mathrm{C}$, i.e., above the $\delta$ phase solvus, resulted in grain boundaries devoid of $\delta$ phase. Solution treatment is followed by two-step aging to strengthen the material by precipitation hardening. However, the aging procedures developed for cast/wrought Alloy 718 are typically employed for EBM-built material [12-14]. This philosophy is also reflected in the ASTM F3055 standard for powder bed fusion built Alloy 718 [19], which states a range of HIPing temperature, and heat treatment conditions apparently unchanged from the existing AMS 5363 standard for cast [20] and AMS 2774 standard for wrought [21] Alloy 718. The conventional aging treatment typically comprises $8 \mathrm{~h}$ of first step of aging (Age1), followed by $2 \mathrm{~h}$ of cooling to second aging (Age2) and holding for $8 \mathrm{~h}$ before cooling. Therefore, it can be represented as ' $8+8^{\prime} \mathrm{h}$ treatment, to represent the holding times at the two steps of aging, and the treatment actually takes $18 \mathrm{~h}$ in total. However, it is clearly evident from the previous studies that the microstructure of Alloy 718 produced by conventional processing methods is particularly different from that produced by EBM or LPBF processes [22-24]. Hence, using typical heat treatments traditionally employed for cast and wrought Alloy 718 for EBM-built material might neither be ideal nor even be necessary, given the $\sim 18 \mathrm{~h}$ duration for the employed treatment. In this context, it is worth mentioning that in a recent study Huang et al. [25] expect accelerated aging response in LPBF Alloy 718 compared to wrought material by studying microstructure evolution during isothermal aging treatment. However, there has been no reported effort on study of microstructure evolution of EBM Alloy 718 during post-treatment. An understanding of evolution of microstructure during thermal post-treatments can aid in designing shorter protocol(s) specifically tailored for EBM Alloy 718 . For completeness, it should also be mentioned that, in general, systematic studies on the influence of posttreatments on the EBM Alloy 718 are limited in the literature.

The present study reports on systematic efforts undertaken for EBM Alloy 718 to understand the evolution of microstructure during heat treatment, which can help to design a shortened optimal posttreatment procedure for EBM Alloy 718 (depending on user, application and desired properties). In addition, the effect of prior HIPing treatment on the microstructure evolution has also been studied. A detailed investigation of grain size, defect content, phase constitution, as well as hardness was carried out at various times during different stages of posttreatment to enable insightful conclusions to be drawn.

\section{Experimental methods}

\section{EBM production of Alloy 718}

The EBM build studied in the present work was supplied by Arcam AB (Mölndal, Sweden). The feedstock Alloy 718 powder used was produced by plasma wire atomization, with a nominal size range of $45-106 \mu \mathrm{m}$ and supplied by AP\&C (Montréal, Canada). The nominal chemical composition of the powder can be seen in Table 1. The EBM build was manufactured using an Arcam A2X machine with a stainless-steel build plate, powder layer thickness of $75 \mu \mathrm{m}$ and $60 \mathrm{kV}$ voltage. The process parameter version, for complete set of process parameters, used in this build was 4.1.22. Bi-directional raster scanning strategy was used for melting the hatch region, and a 
Table 1 Nominal chemical composition of the used Alloy 718 powder

\begin{tabular}{llllllllll}
\hline Element & $\mathrm{Ni}$ & $\mathrm{Cr}$ & $\mathrm{Fe}$ & $\mathrm{Nb}$ & $\mathrm{Mo}$ & $\mathrm{Ti}$ & $\mathrm{Al}$ & $\mathrm{C}$ & $\mathrm{N}$ \\
\hline $\mathrm{wt} \%$ & 51.67 & 19.09 & Rem. & 5.31 & 3.12 & 0.89 & 0.53 & 0.04 & 0.02 \\
\hline
\end{tabular}

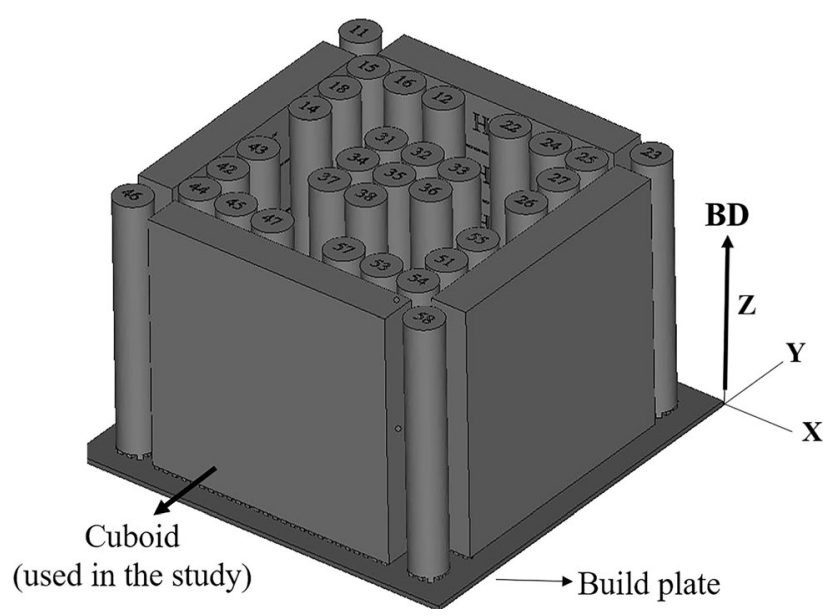

Figure 1 CAD model of the investigated EBM build; the build direction $(\mathrm{BD})$ indicated by the arrow.

line offset of $125 \mu \mathrm{m}$ was used. The build consisted of vertical rods $(100 \times 15 \mathrm{~mm})$ and cuboids $(100 \times 100 \times 15 \mathrm{~mm})$ as shown from the computeraided design (CAD) model presented in Fig. 1. It is worth mentioning that, before initiating the EBM build process, the base plate was pre-heated to $1025{ }^{\circ} \mathrm{C}$. Moreover, the powder bed was also maintained at a high temperature ranging between $800{ }^{\circ} \mathrm{C}$ and $1000{ }^{\circ} \mathrm{C}$ throughout the period of processing.

\section{Thermal post-treatments}

Sections taken from one of the cuboid samples (refer to Fig. 1) were subjected to two different HIP treatments, labeled HIP1 and HIP2. The sectioning was done along the build direction, using water jet cutting, such that a cuboid sample was split into three pieces of dimensions $30 \times 100 \times 15 \mathrm{~mm}$ each. Prior to HIPing, all the specimens were subjected to ultrasonic cleaning. Here it should be mentioned that prior work by authors has already established uniformity in the EBM build [26]. The selection of conditions for HIP1 $\left(1120^{\circ} \mathrm{C}, 100 \mathrm{MPa}, 4 \mathrm{~h}\right)$ and HIP2 $\left(1185{ }^{\circ} \mathrm{C}, 100 \mathrm{MPa}, 4 \mathrm{~h}\right)$ was based on the suggestions in the ASTM F3055 standard for powder bed fusion built Alloy 718 [19]. The $1120^{\circ} \mathrm{C}$ and $1185^{\circ} \mathrm{C}$ temperatures represent the two extremes of the recommended temperature range. Both the HIP treatments were carried out in a molybdenum HIP vessel (Model QIH21, Quintus Technologies, Västerås, Sweden) and using argon as the process gas. For as-built and one of the HIPing conditions chosen based on subsequent results, the specimens were also exposed to various solution treatments (STs), and aging conditions, as given in Table 2. Here it should be mentioned that the aging temperatures for Age $1\left(740{ }^{\circ} \mathrm{C}\right)$ and Age2 $\left(635{ }^{\circ} \mathrm{C}\right)$ correspond to the middle points of the temperatures specified in ASTM F3055, which suggests Age 1 at $720{ }^{\circ} \mathrm{C} / 760{ }^{\circ} \mathrm{C}$ and Age2 at $620{ }^{\circ} \mathrm{C} /$ $650{ }^{\circ} \mathrm{C}$, respectively. Similarly, the ASTM F3055 standard specifies an $8 \mathrm{~h}$ duration each for Age1 and Age2, which will henceforth be referred to as the conventional ' $8+8$ ' $\mathrm{h}$ treatment in the present study that strives to explore potential shortening of the above aging treatment. In addition to the above, the as-built and HIPed specimens were also subjected to STs with different cooling rates adopted at the end of the treatment: furnace cooling ( $\mathrm{FC}, \sim 4{ }^{\circ} \mathrm{C} / \mathrm{min}$ ), air cooling (AC, $\sim 100{ }^{\circ} \mathrm{C} / \mathrm{min}$ ) and water cooling (WC, $>1000{ }^{\circ} \mathrm{C} / \mathrm{min}$ ). While the three different types of cooling were adopted to specifically investigate the influence of cooling rates, unless stated otherwise, the WC was adopted for cooling after STs for all other studies. All the heat treatments were performed using an alumina tube furnace (model R120/500/13, Nabertherm $\mathrm{GmbH}$, Germany) in argon environment. For each treatment, first the furnace was pre-heated to the required holding temperature, and then the specimens were inserted into the furnace and the hold time was counted directly after inserting the samples.

\section{Material characterization}

For microstructural analysis, 5-10-mm-long sections along the build direction were taken from the middle portion (nearly 40-60 $\mathrm{mm}$ from the bottom) of the cuboid (refer to Fig. 1) in as-built and various posttreated conditions. All the samples were hot-mounted and metallographically ground and polished using typical metallographic procedure. In addition to the above, sections perpendicular to the build direction were also prepared for grain structure analysis. To 
Table 2 Designations and details of the post-treatments

\begin{tabular}{ll}
\hline Nomenclature & Post-treatment details \\
\hline HIP1 & $1120{ }^{\circ} \mathrm{C}, 100 \mathrm{MPa}, 4 \mathrm{~h}, \mathrm{RC}\left(>300{ }^{\circ} \mathrm{C} / \mathrm{min}\right)$ \\
HIP2 & $1185{ }^{\circ} \mathrm{C}, 100 \mathrm{MPa}, 4 \mathrm{~h}, \mathrm{RC}\left(>300{ }^{\circ} \mathrm{C} / \mathrm{min}\right)$ \\
ST1 & $980{ }^{\circ} \mathrm{C}$, varying duration $(15 \mathrm{~min}, 30 \mathrm{~min}, 45 \mathrm{~min}, 60 \mathrm{~min}), \mathrm{WC}$ \\
ST2 & $954{ }^{\circ} \mathrm{C}, 60 \mathrm{~min}, \mathrm{WC}$ \\
Age1 & $740{ }^{\circ} \mathrm{C}$, varying duration $(1 \mathrm{~h}, 4 \mathrm{~h}, 8 \mathrm{~h})$, AC \\
Age1 + Age2 & $740{ }^{\circ} \mathrm{C}, 8 \mathrm{~h}, \mathrm{FC}$ at $55^{\circ} \mathrm{C} / \mathrm{h}$ to $635^{\circ} \mathrm{C}$, held at $635^{\circ} \mathrm{C}$ for varying duration $(1 \mathrm{~h}, 4 \mathrm{~h}, 8 \mathrm{~h})$, followed by AC \\
Short age ' $4+1$ & $740{ }^{\circ} \mathrm{C}, 4 \mathrm{~h}, \mathrm{FC}$ at $55^{\circ} \mathrm{C} / \mathrm{h}$ to $635^{\circ} \mathrm{C}$, held at $635^{\circ} \mathrm{C}$ for $1 \mathrm{~h}$, followed by AC \\
\hline
\end{tabular}

$R C$ rapid cooling, FC furnace cooling, $A C$ air cooling, and $W C$ water cooling

reveal the secondary phases, polished samples along the build direction were electrolytically etched either using oxalic acid or 50\% diluted Kalling's 2 reagent with 2-4 V. The samples were analyzed using an optical microscope (OM) (Olympus BX60 M, HOFSTRAgroup ${ }^{\circledR}$, US) and three different scanning electron microscopes (SEMs) (HITACHI TM3000, Japan, LEO 1550 Gemini and Gemini 450, Zeiss, Germany). Image analysis was used for quantification of defect and carbide content (using ASTM E1245-03 automatic image analysis method [27] and the ImageJ software) using at least 10 images in each case, and the average values and $95 \%$ confidence interval have been reported as recommended in the above ASTM standard. Vickers microhardness testing (HMV-2, Shimadzu Corp., Japan) on the unetched samples was done using $500 \mathrm{~g}$ load applied for $15 \mathrm{~s}$. For each of the specimens tested, 15 indents were recorded.

\section{Results and discussion}

The present study mainly focused on the microstructural evolution during the course of heat treatments, involving ST and aging, to possibly shorten the heat treatment protocol for EBM Alloy 718. Given that ST is typically preceded by HIPing for defect closure, the effect of prior HIPing on the subsequent microstructure evolution has also been investigated. Since HIPing can have significant impact on the microstructure, first only the effect of HIPing has been described in detail.

\section{Effect of hot isostatic pressing}

Alloy 718 samples produced by EBM were subjected to two HIPing treatments, as beforementioned, HIP1 $\left(1120{ }^{\circ} \mathrm{C}\right.$, $100 \mathrm{MPa}, 4 \mathrm{~h}$, rapid cooling) and HIP2 $\left(1185^{\circ} \mathrm{C}, 100 \mathrm{MPa}, 4 \mathrm{~h}\right.$, rapid cooling). The effect of HIPing treatments on the grains, defects and phases in the material was evaluated and compared to the as-built microstructure as described below.

\section{Grain structure}

The hatch region, i.e., the bulk of the material, of the as-built EBM Alloy 718 comprised columnar grains elongated along the build direction, where the length of the grains was in the order of $\mathrm{mm}$ and the width of the grains was in the range of $10-100 \mu \mathrm{m}$. This is evident from the low and high magnification micrographs of the as-built EBM Alloy 718 given in Figs. $2 a, b$ and $3 a, b$. Such grain structure is typically observed in the hatch region of the EBM Alloy 718 as reported and elaborated in several studies $[9,10,18]$. It should be mentioned that the bulk of the material was mainly comprised of hatch region, and the contour region forms a relatively narrow 'border' ( $1.5 \mathrm{~mm}$ wide).

After subjecting the material to HIP1 treatment at $1120{ }^{\circ} \mathrm{C}$, no evident effect on the grains was observed in the hatch region as shown in Figs. 2c, d and 3c, d, which reveal micrographs in the build direction and in the transverse direction, respectively. Largely similar response was observed after subjecting the material to HIP2 treatment at $1185{ }^{\circ} \mathrm{C}$ either, as shown in Figs. $2 \mathrm{f}$ and 3f. However, at lower magnification, localized grain growth in the hatch region, particularly in the vicinity of the contour region was observed (see Figs. 2e, 3e). This could be explained by the high susceptibility to grain growth during HIPing in the contour region compared to the hatch region. These results corroborate the observations of Balachandramurthi et al. [9], who have also reported 
Figure 2 Low- and highmagnification SEM

micrographs along the build direction revealing grain structure in the $\mathbf{a}-\mathbf{b}$ as-built condition, and after HIPing: $\mathrm{c}-$ d HIP1 and e-f HIP2. The arrow indicates the build direction.

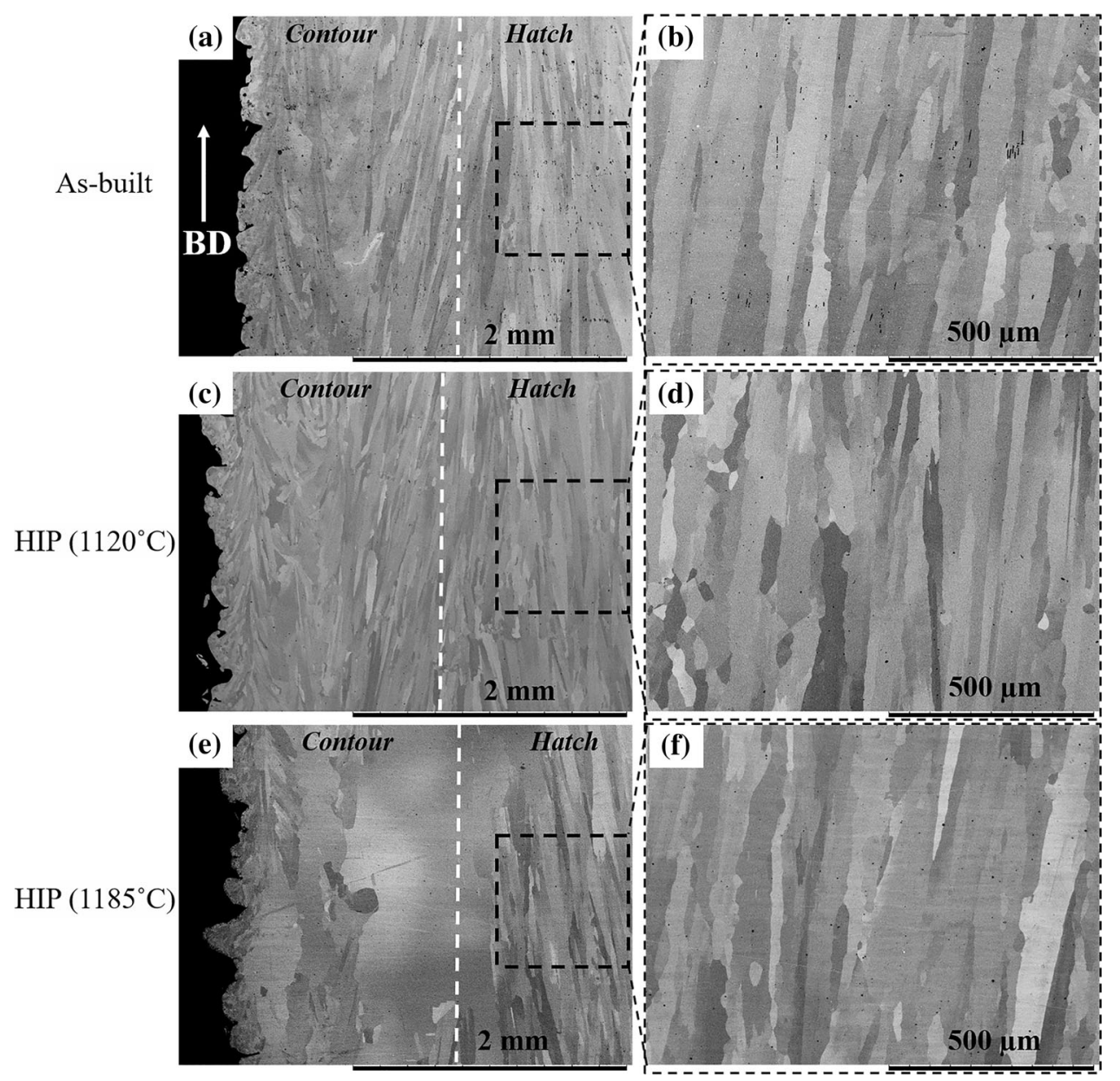

the grain growth after HIPing of EBM Alloy 718 at $1200{ }^{\circ} \mathrm{C}$ to be mainly restricted to the contour region. In other studies employing HIPing at $1200{ }^{\circ} \mathrm{C}$, too, extensive grain growth in the hatch region was observed [12, 26].

\section{Defect analysis}

Three types of defects were present in the as-manufactured condition, i.e., gas porosity, shrinkage porosity and lack-of-fusion. These defects are typically observed in EBM Alloy 718 [6, 28]. The average defect content in the as-built condition was observed to be $\sim 0.15 \%$. However, after both the HIP treatments, it was reduced to $<0.04 \%$ as shown in Fig. $4 \mathrm{a}$ and visualized in Fig. $4 \mathrm{c}$ and d. Thus, after both the HIP treatments, it is evident that similar reductions in the defect content were achieved. In the case of LPBF Alloy 718, Tillmann et al. [17] have also reported HIPing at $1120{ }^{\circ} \mathrm{C}$ and $1185{ }^{\circ} \mathrm{C}$ to result in similar densification. Therefore, HIPing at lower temperature, i.e., $1120{ }^{\circ} \mathrm{C}$ appears promising and is preferred as HIP2 treatment at higher temperature $\left(1185{ }^{\circ} \mathrm{C}\right)$ provided no additional benefits but promoted grain growth. Hence, material subjected to HIP1 treatment was further characterized for phase constitution.

\section{Phase constitution}

In addition to defect reduction, HIPing could also influence secondary phases present in the material. Figure 5a shows network-like features present in the as-built material and these are identified at high magnification to be $\delta$ phase particles (see Fig. $5 b$ ). Such network of $\delta$ phase has also been previously noted in EBM Alloy $718[29,30]$. Moreover, $\gamma^{\prime \prime} / \gamma^{\prime}$ phase particles were also seen in the as-built condition. The reasonably precipitate-free zone observed around the $\delta$ phase could be ascribed to the $\gamma^{\prime \prime} \rightarrow \delta$ phase reaction, where the metastable phase transforms into thermodynamically stable form in the 
Figure 3 Low- and highmagnification SEM

micrographs in the transverse direction revealing grain structure in the $\mathbf{a}-\mathbf{b}$ as-built condition, and after HIPing: $\mathbf{c}-$ d HIP1 and e-f HIP2.
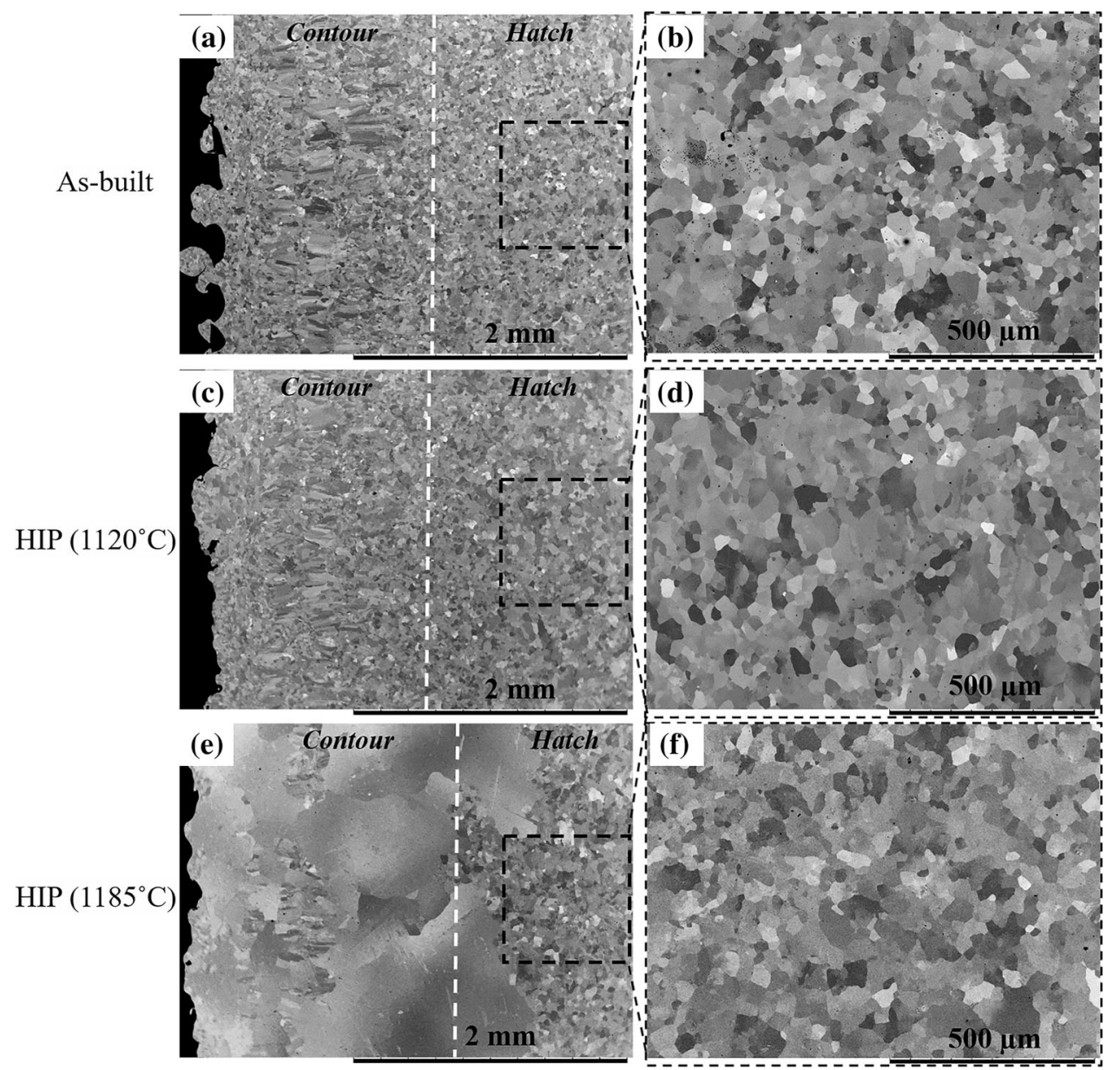

heated powder bed, as typically reported in literature $[31,32]$. Alternatively this could also be attributed to precipitation of $\delta$ phase directly from the matrix which takes up the key alloying element $\mathrm{Nb}$ which is also needed for formation of the $\gamma^{\prime \prime}$ phase, the main hardening phase in Alloy 718 [29, 33]. After subjecting the material to HIP1 treatment, all these precipitates ( $\delta$ phase network, $\gamma^{\prime \prime} / \gamma^{\prime}$ phases) disappeared as shown in low- and high-magnification micrographs in Fig. 5c, d. HIPing treatment caused dissolution of these secondary phases, since all of these had lower solvus temperatures than $1120^{\circ} \mathrm{C}$ employed during HIPing $\left(\delta, \gamma^{\prime \prime} / \gamma^{\prime}\right.$ phases dissolve above $\sim 1010{ }^{\circ} \mathrm{C}$ and $900{ }^{\circ} \mathrm{C}$, respectively [34-36]), and thereby promoted homogenization of the material as these precipitates are rich in alloying elements. This is further corroborated by the consequent decrease in hardness from $435 \mathrm{kgf} / \mathrm{mm}^{2}$ in the as-built condition to 200 $\mathrm{kgf} / \mathrm{mm}^{2}$ after HIP1 treatment. Previous studies have attributed hardness of $200 \mathrm{kgf} / \mathrm{mm}^{2}$ for EBM Alloy 718 with such columnar microstructure to be attributable to absence of strengthening $\gamma^{\prime \prime} / \gamma^{\prime}$ phases
[37]. The globular $\mathrm{NbC}$ carbide particles present in the as-built condition were retained after HIP treatments and quantitatively no change in their amount and size was observed. Further on, investigation of microstructural evolution during heat treatments was carried out using the as-built specimens and samples subjected to HIP1 treatment $\left(1120{ }^{\circ} \mathrm{C}, 4 \mathrm{~h}, 100 \mathrm{MPa}\right)$.

\section{Effect of heat treatments}

Alloy 718 is typically subjected to ST and aging; therefore, evolution of microstructure during these two stages was comprehensively investigated by systematically withdrawing samples periodically during the course of the ASTM recommended cycles [19].

\section{Solution treatment}

The evolution of material during ST was investigated with and without prior HIPing. Moreover, the microstructure evolution can be influenced by the 
Figure 4 Defect content and corresponding $\mathrm{OM}$

micrographs revealing defects in $\mathbf{b}$ as-built condition and after HIPing: c HIP1 and d HIP2.

Figure 5 SEM micrographs at low- and high-magnification showing secondary phase particles in the $\mathbf{a}$ and $\mathbf{b}$ asbuilt, and $\mathbf{c}$ and $\mathbf{d}$ HIPed (HIP1) condition.
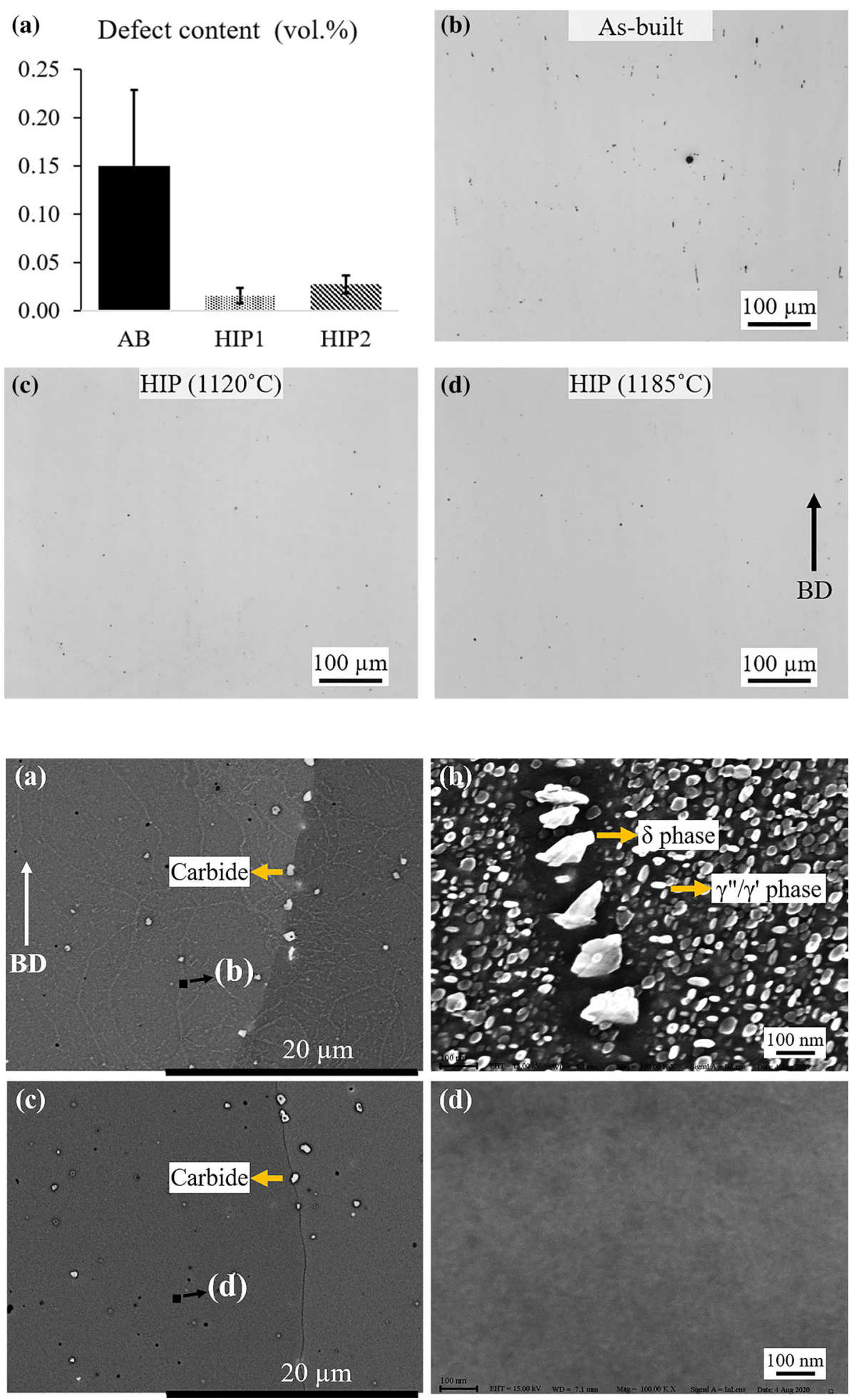

temperature for ST; therefore, the effect of temperature was also investigated. Samples with and without prior HIP1 treatment were subjected to ST for different times. The evolution of microstructure during the typical $1 \mathrm{~h}$ of ST at $980{ }^{\circ} \mathrm{C}$ (ST1) is visualized in
Fig. 6. During ST, mainly the $\delta$ phase was found to precipitate and evolve at the grain boundaries, and interestingly intragranular $\delta$ phase particles (Fig. 5b) were not observed after ST. Deng et al. [18] have also observed grain boundary $\delta$ phase precipitation after 
Figure 6 SEM micrographs showing evolution of $\delta$ phase during ST1 for a-d as-built and $\mathbf{e}-\mathbf{h}$ HIPed (HIP1) material. The arrow indicates the build direction.
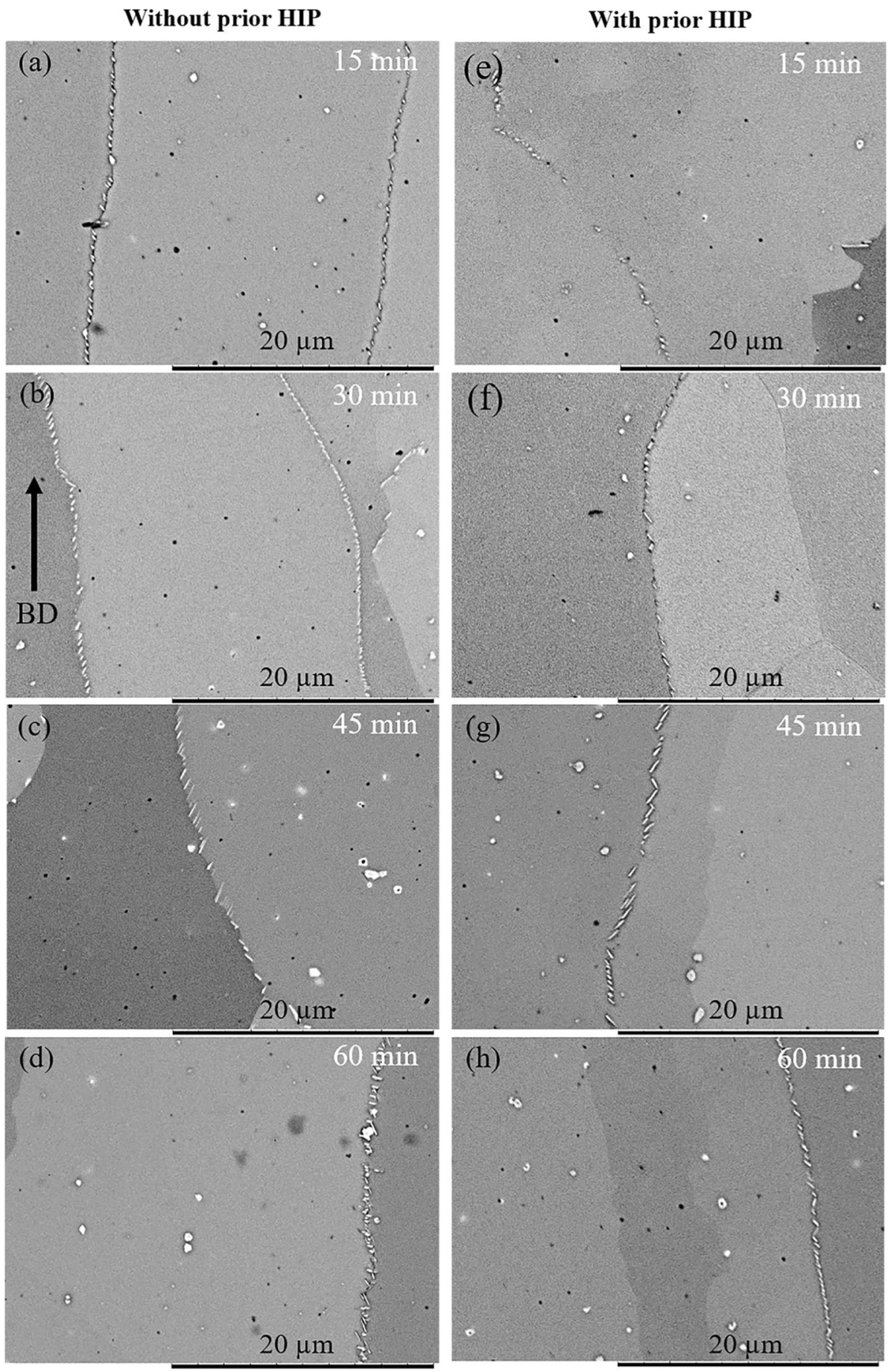

subjecting EBM Alloy 718 to ST at $980{ }^{\circ} \mathrm{C}$ for $1 \mathrm{~h}$. It needs to be mentioned that for the studied time/ temperature of ST, a reliable quantitative analysis of the $\delta$ phase fraction is difficult due to the small size and volume fraction of the particles [38, 39] and hence qualitative comparisons have been made. The $\delta$ phase appeared to grow for nearly the whole 1-h duration of ST. Such evolution of $\delta$ phase was observed irrespective of whether or not the samples were subjected to prior HIPing, although prior HIPing appeared to reduce the amount of $\delta$ phase precipitation during ST. This could be rationalized by the aforementioned increased homogenization after HIPing (refer to Fig. 5). Simulation results have 
shown a decrease in the equilibrium volume fraction of $\delta$ phase due to reduced elemental segregation [40]. Mitchell et al. [41] have also experimentally observed precipitation of $\delta$ phase to be highly dependent on the local $\mathrm{Nb}$ concentration. It should also be mentioned that the $\delta$ phase was observed to precipitate non-uniformly at the grain boundaries in the present study. This could be rationalized by the preferential precipitation of $\delta$ phase at the large angle grain boundaries as observed by Deng et al. [18]. In this context, it is pertinent to mention that the $\delta$ phase is incoherent with the $\gamma$ matrix, and precipitation at grain boundaries, especially high angle grain boundary, is energetically more favorable compared to intragranular precipitation [42]. Previous work has clearly shown that the $\delta$ phase precipitates at the $\gamma$ grain boundary and can grow inside the $\gamma$ grain at the expense of the $\gamma^{\prime \prime}$ precipitates [43].

Apart from precipitation of $\delta$ phase, ST of as-built specimens for only $15 \mathrm{~min}$ resulted in reduction in hardness of the material $\left(200 \mathrm{kgf} / \mathrm{mm}^{2}\right)$ as previously noted after HIPing. Prolonged duration of ST did not have any further effect on the hardness. Moreover, subjecting the samples to ST without prior HIPing had no apparent effect on the carbide, defect contents, and grain size throughout the evolution time, which was as expected. The defect content after ST depended on whether or not prior HIPing was applied. Therefore, it can be inferred that the ST investigated in the present study only influenced $\delta$ and $\gamma^{\prime \prime} / \gamma^{\prime}$ phases in the material. Thus, if HIPing is used to reduce defects, ST could be redundant unless the $\delta$ phase is considered necessary, as the typically required homogenization after ST was also achieved through HIPing [44]. This is of course depending on the properties required and intended application. Deng et al. [18] have also raised concerns about ST step being redundant during posttreatment of EBM Alloy 718. However, the impact of $\delta$ phase on the mechanical response of EBM Alloy 718 needs to be studied in detail as the findings from prior reports on Alloy 718 have been diverse and inconclusive $[18,45,46]$.

Previous studies have shown that ST temperature can influence microstructure evolution [39]. In this context, it should be mentioned that ST temperatures of $980{ }^{\circ} \mathrm{C}$ and $954{ }^{\circ} \mathrm{C}$ are commonly used for Alloy 718 [47]. Thus, samples in as-built and HIPed conditions were also subjected to ST at a different temperature of $954{ }^{\circ} \mathrm{C}$ (ST2). It should also be mentioned that the ST temperatures $\left(980^{\circ} \mathrm{C}\right.$ and $954^{\circ} \mathrm{C}$ ) were selected in this study to precipitate $\delta$ phase [48], and $\delta$ phase solvus temperature is around $1010^{\circ} \mathrm{C}$ [34]. Although not included here for the sake of brevity, similar evolution of $\delta$ phase was observed during the course of ST2 as noted above for ST1 performed at $980{ }^{\circ} \mathrm{C}$, i.e., irrespective of whether or not prior HIPing was performed, $\delta$ phase appeared to grow for nearly the whole 1-h duration of the treatment. In addition, samples subjected to prior HIPing appeared to exhibit lower amount of $\delta$ phase compared to those without prior HIPing. Therefore, from the microstructure evolution point of view it appears that there is not much scope for shortening the STs typically carried out for Alloy 718. A further interesting observation is the amount of $\delta$ phase precipitation after ST at the two investigated temperatures.

The microstructures resulting after ST $1\left(980^{\circ} \mathrm{C}\right)$ and ST2 $\left(954{ }^{\circ} \mathrm{C}\right)$ treatments carried out for a constant duration of 1 h are depicted in Fig. 7, wherein the grain boundaries with $\delta$ phase precipitates appeared highlighted (in black) in the OM images. The OM micrographs were used to qualitatively assess extent of $\delta$ phase precipitation. It is evident from the figure that samples subjected to ST2 treatment resulted in more populous $\delta$ phase precipitation at the grain boundaries compared to those subjected to the ST1 treatment. Similar observations were made regardless of whether or not the specimens were prior HIPed; compare Fig. $7 \mathrm{~b}$ and $\mathrm{d}$. The qualitative difference in the extent of precipitation of $\delta$ phase during ST1 and ST2 can be rationalized by the amount of undercooling. The larger undercooling during ST2 increased the driving force for $\delta$ phase formation (solvus $\sim 1010{ }^{\circ} \mathrm{C}$ ) and therefore caused increased precipitation of the $\delta$ phase. Previous study on EBM Alloy 718 has reported grain boundary precipitation of $\delta$ phase upon ST at $930{ }^{\circ} \mathrm{C}$ and $980^{\circ} \mathrm{C}$; however, the $\delta$ phase content was not investigated [18]. An earlier study on wrought Alloy 718 quantified $\delta$ phase and showed higher amount of $\delta$ phase formation after ST at $950{ }^{\circ} \mathrm{C}$ compared to $975{ }^{\circ} \mathrm{C}$; both treatments performed for a constant duration of $2 \mathrm{~h}$ [39]. Simulation results have also shown higher equilibrium volume fraction of $\delta$ phase at $954{ }^{\circ} \mathrm{C}$ than at $980{ }^{\circ} \mathrm{C}$ [40]. Therefore, depending on the required microstructural properties appropriate ST conditions should be employed, as increase in $\delta$ phase content has been reportedly associated with reduced amount of strengthening phase $\gamma^{\prime \prime}$ [49], because precipitation of both $\delta$ and $\gamma^{\prime \prime}$ phases compete for available $\mathrm{Nb}$ in the material [50]. 
Figure $7 \mathrm{OM}$ micrographs revealing grain boundaries highlighted by $\delta$ phase precipitates after the as-built and HIPed (HIP1) samples were subjected to ST for $1 \mathrm{~h}$ at a, b $980{ }^{\circ} \mathrm{C}$ (ST1) and c, d $954{ }^{\circ} \mathrm{C}$ (ST2), respectively. The inset in $\mathrm{c}$ shows an SEM image of the $\delta$ phase at higher magnification from the marked region in the OM micrograph. The build direction is indicated by the arrow.

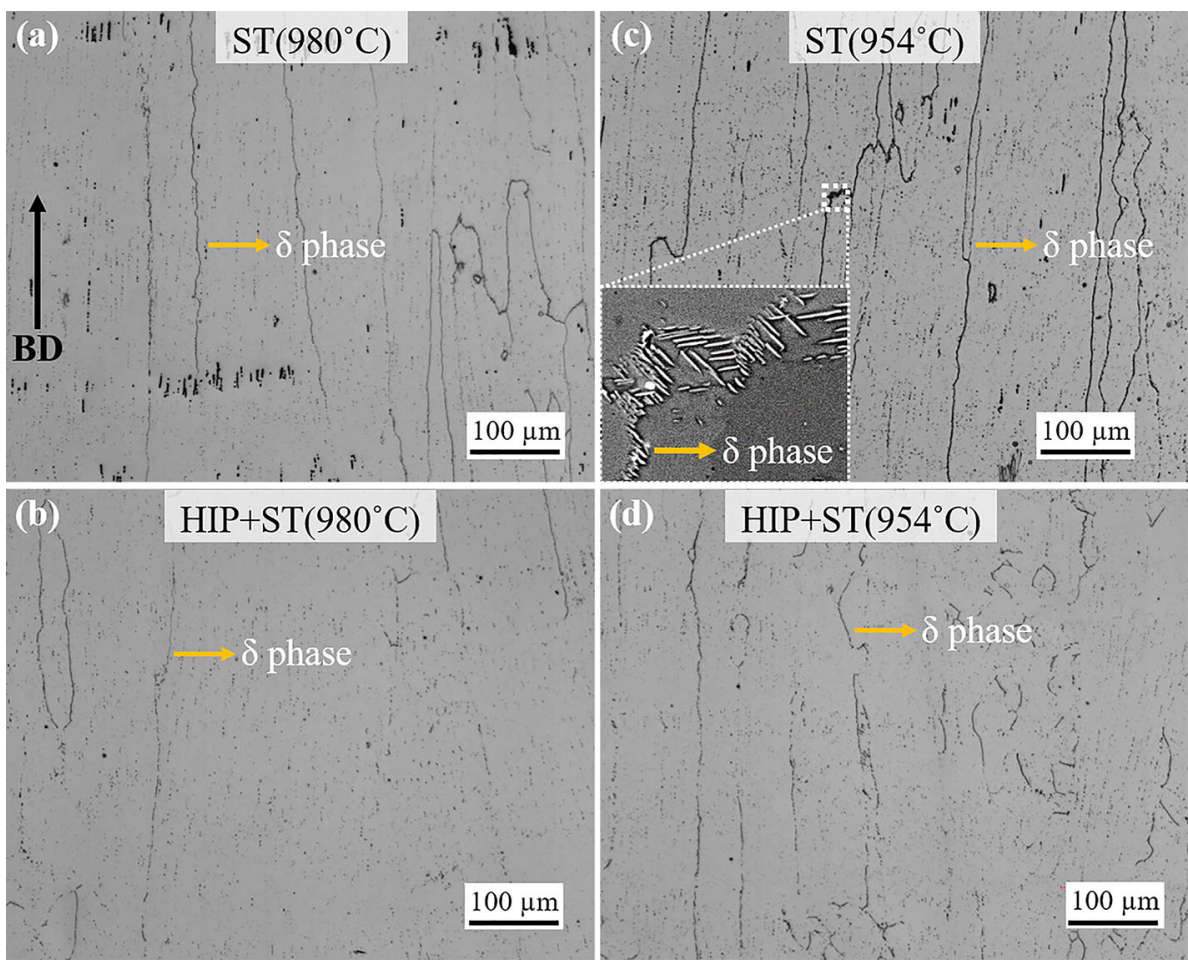

\section{Aging}

The aging protocol for EBM Alloy 718 as recommended in ASTM F3055 includes ' $8+8$ ' $\mathrm{h}$ long twostep aging (Age1 + Age2), which is analogous to the typical aging treatment applied to wrought Alloy 718 [19]. Therefore, in the present work, evolution of microstructure during the above aging treatment was investigated. Since the strengthening effect by aging has a positive correlation with the microhardness of the material [25], the evolution during aging was first characterized by the microhardness values, before undertaking extensive characterization of specimens. The microhardness of precipitation-hardened Alloy 718 can be described by:

$H_{\text {total }}=H_{\text {matrix }}+H_{\mathrm{ps}}$

where $H_{\text {total }}$ is the total hardness, $H_{\text {matrix }}$ denotes the solid solution strengthening in the matrix, and $H_{\mathrm{ps}}$ is contributed by the precipitation strengthening [51]. It should also be mentioned that the hardness can also be influenced by a change in grain size as previously reported for LPBF Alloy 718 [52]. However, in the present study, there was no evident change in grain size during HIP1, ST1 or any of the aging treatments. Therefore, hardness results during aging treatments mainly represented evolution in $H_{\mathrm{ps}}$ with associated changes in $H_{\text {matrix }}$.

For studying evolution during aging, twelve asbuilt specimens were given ST1 for $1 \mathrm{~h}$, and six of these samples were exposed to prior HIP1 treatment. Three each of HIP1 + ST1 and ST1 samples (six in total) were given only Age1 treatment (at $740{ }^{\circ} \mathrm{C}$ ) for varied times $1 \mathrm{~h}, 4 \mathrm{~h}$, and $8 \mathrm{~h}$, respectively. The remaining six specimens (three HIP1 + ST1, three ST1) were first subjected to a common Age1 treatment for $8 \mathrm{~h}$, and after that they were given Age2 treatment (at $635^{\circ} \mathrm{C}$ ) for varied times- $1 \mathrm{~h}, 4 \mathrm{~h}$, and $8 \mathrm{~h}$, respectively. The microhardness values of all the above specimens were evaluated and are summarized in Fig. 8. It can be seen from Fig. 8a that the hardness of the material was considerably decreased after HIP1 treatment and subsequent ST1 treatment had no evident effect. If the specimens were not prior-HIPed, a reduction in hardness (similar to that observed in HIPed specimens) was noted after ST (see Fig. 8b). In both cases, the reduction in hardness was attributable to dissolution of strengthening precipitates. The hardness of the specimens "recovered" during aging.

During the course of Age1 treatment, the hardness increased with increase in aging time up to $4 \mathrm{~h}$, but with prolonged holding at Age1 temperature past 
Figure 8 Microhardness evolution during aging of samples subjected to ST1 treatment $\mathbf{a}$ with and $\mathbf{b}$ without prior HIPing (HIP1); with reference to hardness in asbuilt $(\mathrm{AB})$ condition. The ASTM suggested minimum value of hardness for Alloy $718\left(350 \mathrm{kgf} / \mathrm{mm}^{2}\right)$ being indicated by the dashed line [19]. Here A1 and A2 imply Age1 (at $740{ }^{\circ} \mathrm{C}$ ) and Age2 (at $635^{\circ} \mathrm{C}$ ), respectively.
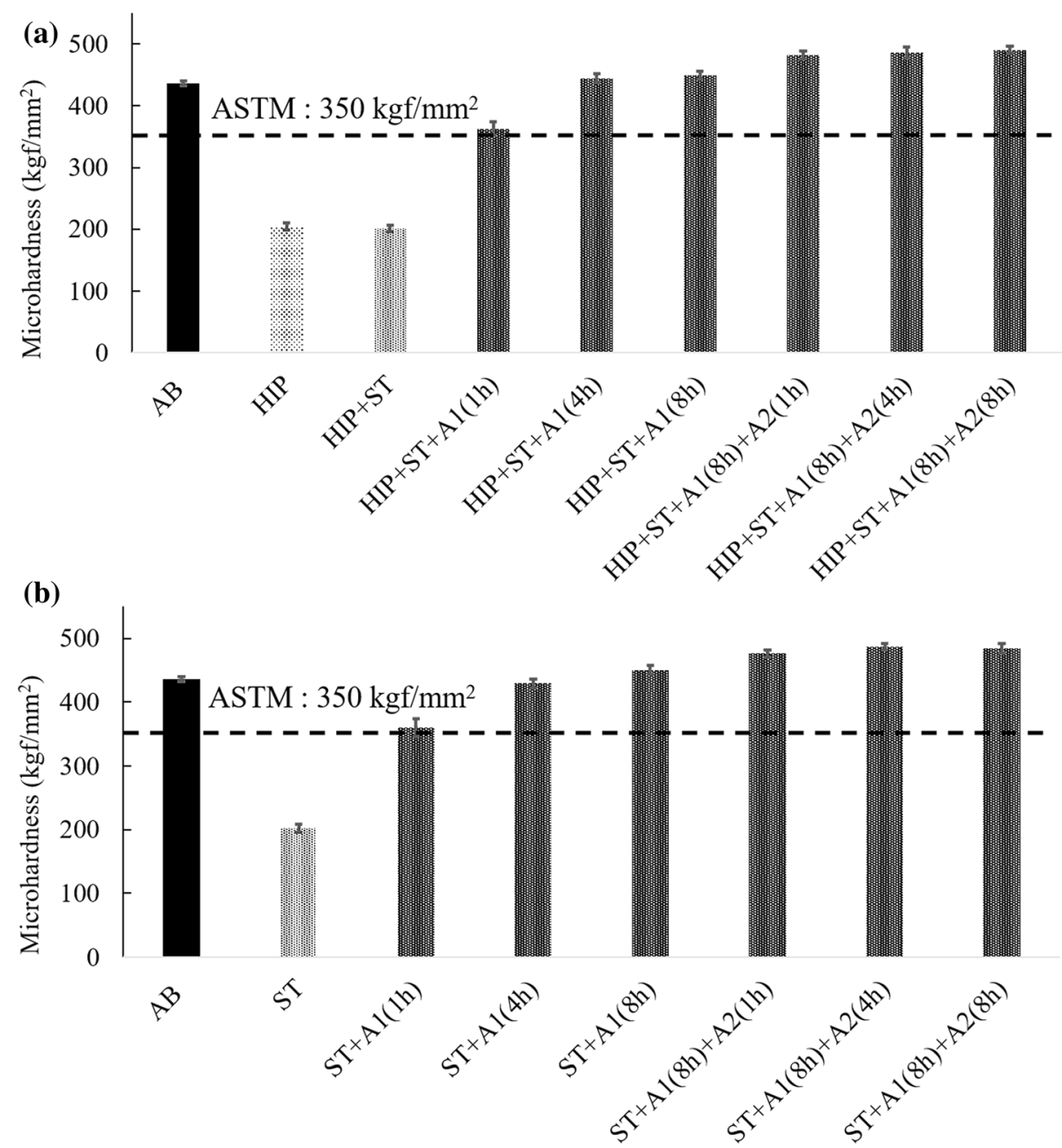

$4 \mathrm{~h}$, no additional increase in hardness was observed. Similarly, after Age2 treatment, the hardness increased after $1 \mathrm{~h}$ of treatment, and longer times did not yield any further increase in hardness. Similar observations were made irrespective of whether or not the samples were subjected to prior HIPing (refer to Fig. 8). However, when HIPing was not employed, the defects were found to have been retained after the post-treatment. From the above observations, it appears that the hardness values flatten after $4 \mathrm{~h}$ of Age1 treatment and after $1 \mathrm{~h}$ of Age2 treatment.

It should also be mentioned that in the case of $\mathrm{ST}+$ Age for varied aging conditions and without prior HIPing, some intragranular $\delta$ phase particles were observed. The intragranular $\delta$ phase particles could be attributed to elemental segregation retained even after ST. An earlier study on wrought Alloy 718 has shown precipitation of $\delta$ phase after aging at $732{ }^{\circ} \mathrm{C}$ for $8 \mathrm{~h}$ and the $\delta$ phase exhibited a different chemistry from the one formed at $954{ }^{\circ} \mathrm{C}$ [53]. In the case of ST + Age with prior HIPing, intragranular $\delta$ phase particles were not observed, which could be rationalized by the aforementioned significantly reduced elemental segregation after HIPing. The HIPing treatment is particularly considered important for defect reduction because after HIP + ST + Aging the defect content was reduced by an order of magnitude, whereas after ST + Aging it was similar to the as-built condition. Thus, further microstructure characterization was carried out for aged samples subjected to prior HIPing and ST.

To further assess evolution of the hardening phases, $\gamma^{\prime \prime} / \gamma^{\prime}$, during the course of aging, high-resolution SEM imaging was employed. It can be seen from Fig. 9 that there is significant growth of the particles when proceeding from 1 to $4 \mathrm{~h}$ of Age1 with prior HIP1 + ST1. Thereafter, with prolonged duration of Age 1 to $8 \mathrm{~h}$ no evident change in the size of precipitates was 
Figure 9 High-resolution SEM micrographs of aged HIP1 + ST1 samples showing the evolution of strengthening precipitates during Age1 after a $1 \mathrm{~h}, \mathbf{b} 4 \mathrm{~h}$ c $8 \mathrm{~h}$, and after Age1 $(8 \mathrm{~h})+$ Age2 treatments: $\mathbf{d}$ ' $8+1$ ' $\mathrm{h}$ and e ' $8+4$ ' $\mathrm{h}$; build direction indicated by the arrow.
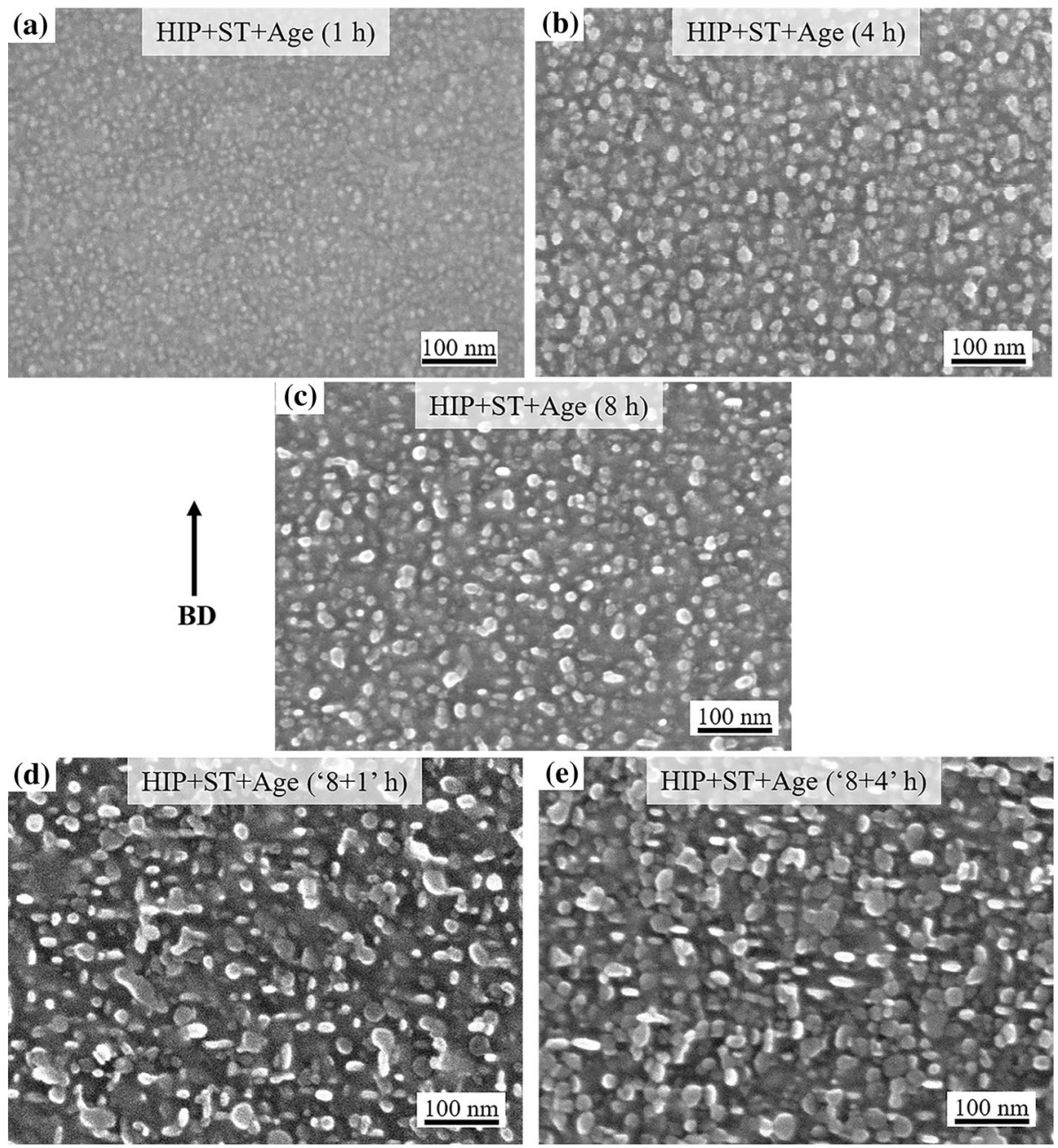

observed. With further increased duration of aging, i.e., after Age2 treatment for $1 \mathrm{~h}$ with prior Age 1 for $8 \mathrm{~h}$ $(' 8+1$ ' $h)$, slight increase in the size of precipitates was observed. Prolonged duration of Age2 treatment $\left({ }^{\prime} 8+4^{\prime}\right.$ h) yielded no evident change.

\section{Potential to design shorter tailored post- treatment for EBM Alloy 718}

The foregoing results showed the EBM Alloy 718 can be subjected to HIPing at lower temperature, i.e., $1120{ }^{\circ} \mathrm{C}$ to remove defects and promote homogenization while suppressing grain growth, whereas HIPing at higher temperature, i.e., $1185^{\circ} \mathrm{C}$, can cause grain coarsening and provides no additional benefits. Hot isostatic pressing is required for densification as heat treatments involving ST and aging had no evident effect on the defects.

The ST, if needed, can be carried out at $954{ }^{\circ} \mathrm{C}$ or $980{ }^{\circ} \mathrm{C}$ for a duration of $1 \mathrm{~h}$; the choice of temperature would depend on the required extent of $\delta$ phase precipitation at the grain boundaries. In this context, it should also be mentioned that the cooling rate after ST can be controlled to precipitate strengthening phases. A study on wrought Alloy 718 has shown that variation in cooling rate after ST can significantly influence hardness of the material due to precipitation (or lack) of $\gamma^{\prime \prime} / \gamma^{\prime}$ phases during cooling [54]. Thus, for designing ST protocol for EBM Alloy 718 cooling rate after ST should also be considered and therefore in the present study the as-built and HIP1 specimens were also subjected to three different cooling modes after ST1, i.e., WC, AC and FC. With the cooling rates in each of these cases differing at least by an order of magnitude (refer to "Thermal post-treatments" section). The samples subjected to FC after ST were found to exhibit highest hardness $\left(420-430 \mathrm{kgf} / \mathrm{mm}^{2}\right)$, while the hardness after AC or WC was the lowest $\left(200-210 \mathrm{kgf} / \mathrm{mm}^{2}\right)$. These observations were recorded irrespective of whether or not the material was subjected to prior HIPing.

\section{Springer}


Since the main strengthening phase, $\gamma^{\prime \prime}$, precipitates in the range of $595-870^{\circ} \mathrm{C}$ [55], its precipitation occurs only during cooling after holding at the ST temperature. In this study, it took nearly $64 \mathrm{~min}$ to cool from 870 to $595{ }^{\circ} \mathrm{C}$ during the $\mathrm{FC}$, thereby providing sufficient time for $\gamma^{\prime \prime}$ phase to precipitate as seen in Fig. 10e and f. In the case of AC and WC, the corresponding durations in the precipitation range of the strengthening phase was $\sim 3 \mathrm{~min}$ and $<1 \mathrm{~min}$, respectively, which are insufficient for $\gamma^{\prime \prime}$ phase precipitation [56] due to its reported sluggish precipitation $[56,57]$. Such effect of the employed cooling rates has also been previously observed in LPBF-built [25] and wrought $[47,54]$ Alloy 718 . The high hardness and significant precipitation of $\gamma^{\prime \prime}$ phase as shown in Fig. 10 achieved through ST with FC reveals interesting prospects in tailoring cooling rate after ST as an alternative to carrying out a separate subsequent aging treatment as also recently reported by Kumara et al. [40]. For instance, in oil-field applications, Special Metals Corp. has suggested a maximum hardness of Alloy 718 to be $40 \mathrm{HRC}\left(382 \mathrm{kgf} / \mathrm{mm}^{2}\right.$ [58]) [59] which is significantly below the peak hardness of the material $\left(\sim 500 \mathrm{kgf} / \mathrm{mm}^{2}\right)$ [18].

To achieve the peak hardness of the material in order to meet the demanding conditions that Alloy 718 is commonly used for, the EBM Alloy 718 is typically precipitation-hardened through two-step aging with prior HIPing and ST (followed by quenching). Investigation of microstructural evolution during the two-step aging revealed prospects for a significantly shortened aging protocol. There is a possibility to shorten the typical ' $8+8$ ' $\mathrm{h}$ treatment to a trimmed ' $4+1$ ' $\mathrm{h}$ treatment when the samples are subjected to prior HIPing and ST treatment. Comparison of micrographs of specimens eventually subjected to the short ' $4+1^{\prime}$ ' $h$ and the
Figure 10 High-resolution SEM micrographs of samples subjected to ST1 treatment $\left(980{ }^{\circ} \mathrm{C}, 1 \mathrm{~h}\right)$, with or without prior HIPing (HIP1), with different cooling modes, i.e., $\mathbf{a}$ and $\mathbf{b}$ water cooling (WC), $\mathbf{c}$ and $\mathbf{d}$ air cooling (AC), and $\mathbf{e}$ and $\mathbf{f}$ furnace cooling (FC).

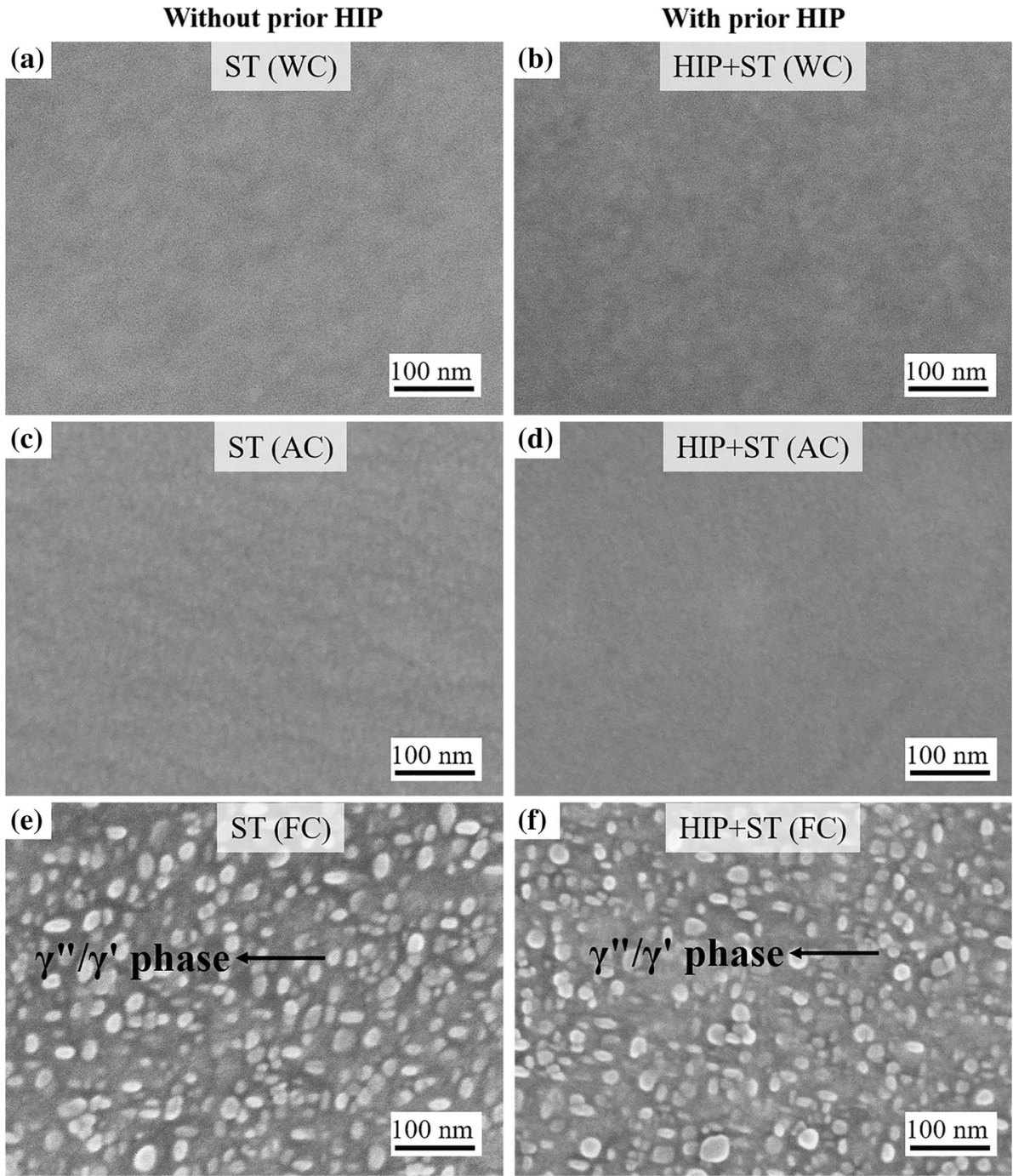


conventional ' $8+8$ ' $\mathrm{h}$ aging revealed similar distribution of $\gamma^{\prime \prime} / \gamma^{\prime}$ precipitates as shown in Fig. 11, and the hardness in the two cases was also reasonably similar, i.e., $473 \pm 15 \mathrm{kgf} / \mathrm{mm}^{2}$ and $490 \pm 6 \mathrm{kgf} / \mathrm{mm}^{2}$, respectively, considering the statistical variation. It should also be mentioned that similar hardness values were obtained when the samples were not subjected to prior HIPing. Another interesting observation was that the precipitates after both ' $4+1^{\prime} \mathrm{h}$ and ' $8+8^{\prime} \mathrm{h}$ aging conditions appeared finer and more than in the as-built condition (with lower hardness $436 \pm 4 \mathrm{kgf} / \mathrm{mm}^{2}$ ). It is also worth mentioning that, after the entire thermal posttreatment cycle involving ST + Aging, with or without prior HIPing, the carbides were observed to be stable. However, the defects were significantly reduced by an order of magnitude when HIPing was employed (0.02\%) as opposed to the case when no prior HIPing was carried out $(0.2 \%)$. Lastly, it is worth noting that the significantly shortened aging developed in this study could speed up the processing of EBM Alloy 718 and could be potentially further tailored depending on the required mechanical properties and intended application.

\section{Summary and conclusions}

The present study describes the effect of various thermal post-treatments steps (HIPing, solution treatment and aging) on the microstructure of EBMmanufactured Alloy 718. Moreover, the effect of variation in post-treatment parameters such as, time, temperature, and cooling rate on the microstructure was also studied. The findings and conclusions drawn from the study, as summarized below, can be used to design tailored post-treatment procedure for EBM Alloy 718.

- HIPing at lower temperature $\left(1120^{\circ} \mathrm{C}\right.$ vs. $\left.1185^{\circ} \mathrm{C}\right)$ can significantly close defects while suppressing grain growth. This suggests that the grain size can be maintained during post-treatment, while achieving the needed defect closure. Subjecting the material to HIPing promoted homogenization by dissolution of secondary phases $\left(\delta, \gamma^{\prime \prime} / \gamma^{\prime}\right.$ phases); however, carbide particles were stable through all the post-treatment steps.

- Solution treatment caused $\delta$ phase precipitation at the grain boundaries. The $\delta$ phase appeared to evolve almost during the entire $1 \mathrm{~h}$ duration of the treatment. The extent of precipitation of $\delta$ phase can be increased by lowering the temperature for solution treatment from 980 to $954^{\circ} \mathrm{C}$. Subjecting the material to prior HIPing reduced extent of $\delta$ phase precipitation.

- Cooling rate after solution treatment had significant effect on the resulting precipitation of strengthening phases and consequently on the hardness of the material.

- The investigated evolution of microstructure and hardness during the course of aging is suggestive of prospect for significantly shortened aging
Figure 11 High-resolution SEM micrographs showing the strengthening precipitates in a as-built, and HIP1 + ST1 samples after b short (' $4+1$ ' h) and c conventional long $(' 8+8$ ' h) aging treatments. The arrow indicates the build direction.

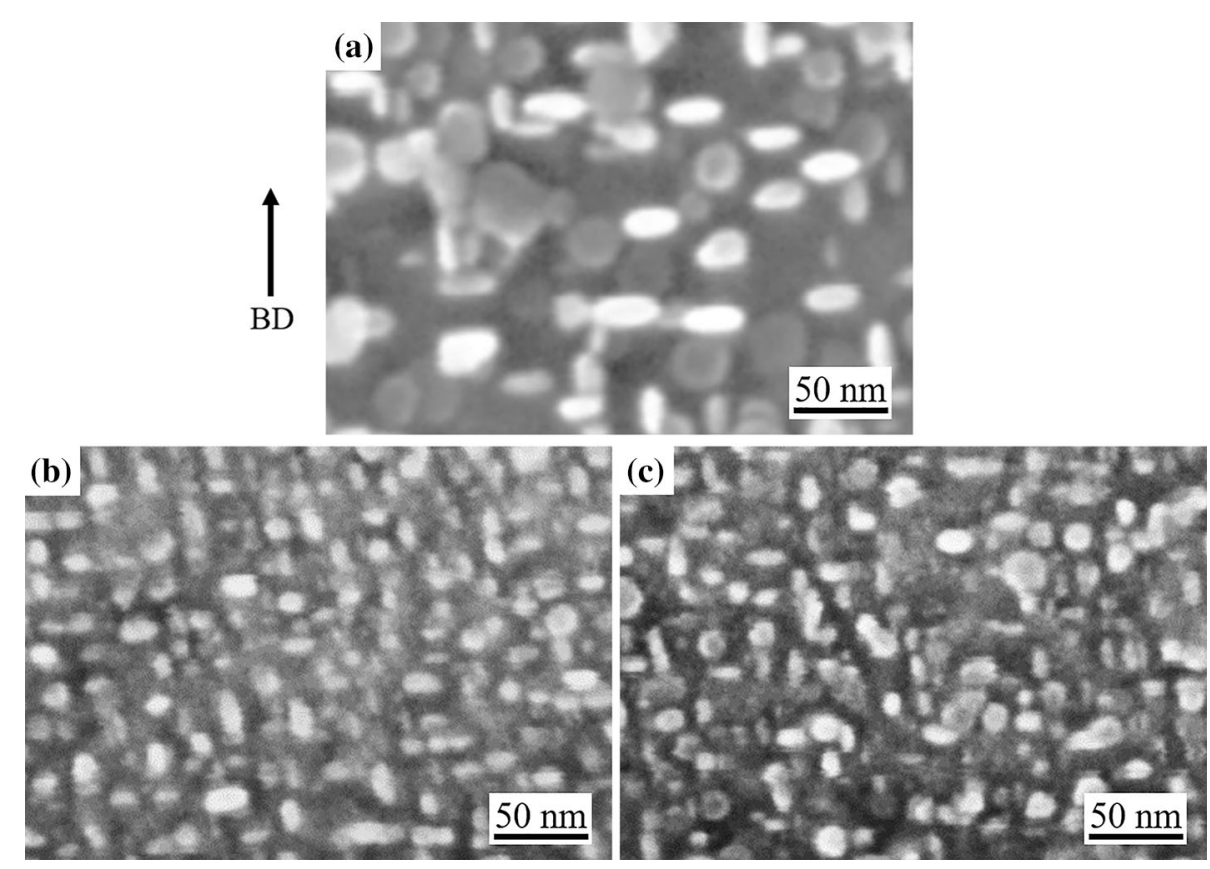


treatment (' $4+1^{\prime}$ h) compared to the 'standard' long treatment (' $8+8^{\prime}$ h) commonly employed for Alloy 718, a reduction in aging time by more than $50 \%$.

\section{Acknowledgements}

The authors thank Dr. Yiming Yao, Chalmers University of Technology, Sweden for assistance with SEM imaging. The authors are grateful to Dr. Fouzi Bahbou, Arcam AB, Sweden for supplying the investigated material. This work was supported by the Stiftelsen för Kunskaps- och Kompetensutveckling, Sweden [Grant Number 20160281] via the SUMAN-Next project.

\section{Funding}

Open access funding provided by University West.

Open Access This article is licensed under a Creative Commons Attribution 4.0 International License, which permits use, sharing, adaptation, distribution and reproduction in any medium or format, as long as you give appropriate credit to the original author(s) and the source, provide a link to the Creative Commons licence, and indicate if changes were made. The images or other third party material in this article are included in the article's Creative Commons licence, unless indicated otherwise in a credit line to the material. If material is not included in the article's Creative Commons licence and your intended use is not permitted by statutory regulation or exceeds the permitted use, you will need to obtain permission directly from the copyright holder. To view a copy of this licence, visit http://creativecommons.org/licen ses/by/4.0/.

\section{Data availability}

The raw/processed data required to reproduce these findings cannot be shared at this time due to technical or time limitations.

\section{References}

[1] Paulonis DF, Schirra JJ (2001) Alloy 718 at Pratt \& Whitney-historical perspective and future challenges. In: Loria EA (ed) Superalloy 718, 625, 706, Var. Deriv., TMS (The Minerals, Metals \& Materials Society), 2001, pp 13-23. h ttps://doi.org/10.7449/2001/superalloys_2001_13_23

[2] Lemke TF, Harris JA (1983) High-alloy materials for offshore applications. In: Proceedings of the annual offshore technology conference, pp 71-75. https://doi.org/10.4043/4 451-ms

[3] Sochalski-Kolbus LM, Payzant EA, Cornwell PA, Watkins TR, Babu SS, Dehoff RR, Lorenz M, Ovchinnikova O, Duty C (2015) Comparison of residual stresses in Inconel 718 simple parts made by electron beam melting and direct laser metal sintering. Metall Mater Trans A 46:1419-1432. http s://doi.org/10.1007/s11661-014-2722-2

[4] Kirka MM, Greeley DA, Hawkins C, Dehoff RR (2017) Effect of anisotropy and texture on the low cycle fatigue behavior of Inconel 718 processed via electron beam melting. Int J Fatigue 105:235-243

[5] Ni M, Liu S, Chen C, Li R, Zhang X, Zhou K (2019) Effect of heat treatment on the microstructural evolution of a precipitation-hardened superalloy produced by selective laser melting. Mater Sci Eng A 748:275-285. https://doi.org/10. 1016/j.msea.2019.01.109

[6] Sames WJ, List FA, Pannala S, Dehoff RR, Babu SS (2016) The metallurgy and processing science of metal additive manufacturing. Int Mater Rev 61:315-360. https://doi.org/ 10.1080/09506608.2015.1116649

[7] Deng D (2018) Additively manufactured Inconel 718: microstructures and mechanical properties. Licentiate Thesis, Linköping University. https://doi.org/10.3384/lic.diva144491

[8] Balachandramurthi AR, Moverare J, Mahade S, Pederson R (2019) Additive manufacturing of Alloy 718 via electron beam melting: effect of post-treatment on the microstructure and the mechanical properties. Materials (Basel) 12:68. h ttps://doi.org/10.3390/ma12010068

[9] Balachandramurthi AR, Moverare J, Dixit N, Deng D, Pederson R (2019) Microstructural influence on fatigue crack propagation during high cycle fatigue testing of additively manufactured Alloy 718. Mater Charact 149:82-94. h ttps://doi.org/10.1016/j.matchar.2019.01.018

[10] Kirka MM, Medina F, Dehoff R, Okello A (2017) Mechanical behavior of post-processed Inconel 718 manufactured through the electron beam melting process. Mater Sci Eng A 680:338-346. https://doi.org/10.1016/j.msea.201 6.10 .069 
[11] Shassere B, Greeley D, Okello A, Kirka M, Nandwana P, Dehoff R (2018) Correlation of microstructure to creep response of hot isostatically pressed and aged electron beam melted Inconel 718. Metall Mater Trans A 49:5107-5117. h ttps://doi.org/10.1007/s11661-018-4812-Z

[12] Nandwana P, Kirka M, Okello A, Dehoff R (2018) Electron beam melting of Inconel 718: effects of processing and postprocessing. Mater Sci Technol 34:612-619. https://doi.org/ 10.1080/02670836.2018.1424379

[13] Unocic KA, Kolbus LM, Dehoff RR, Dryepondt SN, Pint BA (2014) High-temperature performance of UNS N07718 processed by additive manufacturing. In: NACE corrosion, NACE International, San Antonio, USA, 2014. http://www. osti.gov/scitech/biblio/1132980

[14] Kirka MM, Lee YS, Greeley DA, Okello A, Goin MJ, Pearce MT, Dehoff RR (2017) Strategy for texture management in metals additive manufacturing. JOM 69:523-531. https://doi.org/10.1007/s11837-017-2264-3

[15] Chang L, Sun W, Cui Y, Yang R (2014) Influences of hotisostatic-pressing temperature on microstructure, tensile properties and tensile fracture mode of Inconel 718 powder compact. Mater Sci Eng A 599:186-195. https://doi.org/10. 1016/j.msea.2014.01.095

[16] Sames WJ (2015) Additive manufacturing of Inconel 718 using electron beam melting: processing, post-processing, \& mechanical properties. Ph.D. thesis, Texas A\&M University

[17] Tillmann W, Schaak C, Nellesen J, Schaper M, Aydinöz ME, Hoyer K-P (2017) Hot isostatic pressing of IN718 components manufactured by selective laser melting. Addit Manuf 13:93-102. https://doi.org/10.1016/j.addma.2016.11.006

[18] Deng D, Moverare J, Peng RL, Söderberg H (2017) Microstructure and anisotropic mechanical properties of EBM manufactured Inconel 718 and effects of post heat treatments. Mater Sci Eng A 693:151-163. https://doi.org/ 10.1016/j.msea.2017.03.085

[19] ASTM F3055-14a, Standard specification for additive manufacturing Nickel alloy (UNS N07718) with powder bed fusion, ASTM Int. (2014). https://doi.org/10.1520/f3055-14a

[20] AMS5383 (2012) Aerospace material specification. SAE Aerospace

[21] AMS 2774A (2005) Heat treatment: wrought nickel alloy and cobalt alloy parts. AMS

[22] Chamanfar A, Sarrat L, Jahazi M, Asadi M, Weck A, Koul AK (2013) Microstructural characteristics of forged and heat treated Inconel-718 disks. Mater Des 52:791-800. https://d oi.org/10.1016/j.matdes.2013.06.004

[23] Strondl A, Palm M, Gnauk J, Frommeyer G (2011) Microstructure and mechanical properties of nickel based superalloy IN718 produced by rapid prototyping with electron beam melting (EBM). Mater Sci Technol 27:876-883. h ttps://doi.org/10.1179/026708309x12468927349451

[24] Deng D, Peng RL, Brodin H, Moverare J (2018) Microstructure and mechanical properties of Inconel 718 produced by selective laser melting: sample orientation dependence and effects of post heat treatments. Mater Sci Eng A 713:294-306. https://doi.org/10.1016/j.msea.2017.1 2.043

[25] Huang W, Yang J, Yang H, Jing G, Wang Z, Zeng X (2019) Heat treatment of Inconel 718 produced by selective laser melting: microstructure and mechanical properties. Mater Sci Eng A 750:98-107. https://doi.org/10.1016/j.msea.2019.02. 046

[26] Goel S, Ahlfors M, Bahbou F, Joshi S (2019) Effect of different post-treatments on the microstructure of EBM-built Alloy 718. J Mater Eng Perform 28:673-680. https://doi.org/ 10.1007/s11665-018-3712-0

[27] ASTM E1245-03 (2008) Standard practice for determining the inclusion or second-phase constituent content of metals by automatic image analysis. ASTM Int 1-8. https://doi.org/ 10.1520/e1245-03r16

[28] Goel S, Olsson J, Ahlfors M, Klement U, Joshi S (2018) The effect of location and post-treatment on the microstructure of EBM-built Alloy 718. In: Ott E, Liu X, Andersson J, Bi Z, Bockenstedt K, Dempster I, Groh J, Heck K, Jablonski P, Kaplan M, Nagahama D, Sudbrack C (eds) Proceedings of the 9th international symposium on superalloy 718 \& derivatives: energy, aerospace, and industrial applications. The Minerals, Metals \& Materials Series, Pittsburgh, USA, pp 115-129. https://doi.org/10.1007/978-3-319-89480-5_6

[29] Kirka MM, Unocic KA, Raghavan N, Medina F, Dehoff RR, Babu SS (2016) Microstructure development in electron beam-melted Inconel 718 and associated tensile properties. JOM 68:1012-1020. https://doi.org/10.1007/s11837-016-18 12-6

[30] Goel S, Sittiho A, Charit I, Klement U, Joshi S (2019) Effect of post-treatments under hot isostatic pressure on microstructural characteristics of EBM-built Alloy 718 . Addit Manuf 28:727-737. https://doi.org/10.1016/j.addma. 2019.06.002

[31] Pröbstle M, Neumeier S, Hopfenmüller J, Freund LP, Niendorf T, Schwarze D, Göken M (2016) Superior creep strength of a nickel-based superalloy produced by selective laser melting. Mater Sci Eng A 674:299-307. https://doi.org/ 10.1016/j.msea.2016.07.061

[32] Sundararaman M, Mukhopadhyay P, Banerjee S (1988) Precipitation of the $\delta-\mathrm{Ni}_{3} \mathrm{Nb}$ phase in two Nickel base 
superalloys. Metall Trans A 19A:453-465. https://doi.org/ 10.1007/bf02649259

[33] Sundararaman M, Mukhopadhyay P, Banerjee S (1994) Precipitation and room temperature deformation behaviour of Inconel 718. In: Loria EA (ed), Superalloys 718, 625, 706 Var. Deriv., Pittsburgh, PA, USA, 1994, pp 419-440. http s://doi.org/10.7449/1994/superalloys_1994_419_440

[34] Radavich JF (1989) The physical metallurgy of cast and wrought Alloy 718. In: Loria EA (ed) Superalloy 718-metallurgy applications. The Minerals, Metals \& Materials Society, Pittsburgh, PA, USA, 1989, pp 229-240. https://doi. org/10.7449/1989/superalloys_1989 229 240

[35] Strondl A, Fischer R, Frommeyer G, Schneider A (2008) Investigations of MX and $\gamma^{\prime} / \gamma^{\prime \prime}$ precipitates in the nickelbased superalloy 718 produced by electron beam melting. Mater Sci Eng A 480:138-147. https://doi.org/10.1016/j.ms ea.2007.07.012

[36] Niang A, Viguier B, Lacaze J (2010) Some features of anisothermal solid-state transformations in alloy 718. Mater Charact 61:525-534. https://doi.org/10.1016/j.matchar.2010. 02.011

[37] Deng D, Saarimäki J, Söderberg H, Peng RL, Brodin H, Moverare J (2016) Microstructural characterization of asmanufactured and heat treated electron beam melted Inconel 718. In: Materials science and technology, MS\&T, Salt Lake City, UT, USA, 2016, pp 105-112

[38] Thompson RG, Boutwell BA (1994) Microstructure analysis of fine grain Alloy 718 casting. In: Loria EA (ed) Superalloy 718, 625, 706, Var. Deriv., Pittsburgh, PA, USA, 1994, pp 213-228. https://doi.org/10.7449/1994/superalloys_1994 213_228

[39] Anderson M, Thielin A-L, Bridier F, Bocher P, Savoie J (2017) $\delta$ Phase precipitation in Inconel 718 and associated mechanical properties. Mater Sci Eng A 679:48-55. https://d oi.org/10.1016/j.msea.2016.09.114

[40] Kumara C, Balachandramurthi AR, Goel S, Hanning F, Moverare J (2020) Toward a better understanding of phase transformations in additive manufacturing of Alloy 718. Materialia. https://doi.org/10.2139/ssrn.3628004

[41] Mitchell A, Schmalz AJ, Schvezov C, Cockcroft SL (1994) The precipitation of primary carbides in Alloy 718. In: Loria EA (ed) Superalloys 718, 625, 706 Var. Deriv., The Minerals, Metals \& Materials Society, Pittsburgh, PA, USA, 1994, pp 65-78. https://doi.org/10.7449/1994/superalloys 19946 $5 \_78$

[42] Zhang H, Li C, Guo Q, Ma Z, Huang Y, Li H, Liu Y (2017) Delta precipitation in wrought Inconel 718 alloy; the role of dynamic recrystallization. Mater Charact 133:138-145. http s://doi.org/10.1016/j.matchar.2017.09.032
[43] Slama C, Abdellaoui M (2000) Structural characterization of the aged Inconel 718. J Alloys Compd 306:277-284. http s://doi.org/10.1016/s0925-8388(00)00789-1

[44] Donachie MJ, Donachie SJ (2002) Superalloys: a technical guide, 2nd edn. ASM International, Washington

[45] Li S, Zhuang J, Yang J, Deng Q, Du J, Xie X, Li B, Xu Z, Cao Z, Su Z, Jiang C (1994) The effect of $\delta$-phase on crack propagation under creep and fatigue conditions in Alloy 718. In: Loria EA (ed) Superalloys 718, 625, 706 Var. Deriv., The Minerals, Metals \& Materials Society, Pittsburgh, PA, USA, 1994, pp 545-555. https://doi.org/10.7449/1994/superalloy s_1994 545 555

[46] Valle LCM, Araújo LS, Gabriel SB, Dille J, de Almeida LH (2013) The effect of $\delta$ phase on the mechanical properties of an Inconel 718 superalloy. $J$ Mater Eng Perform 22:1512-1518. https://doi.org/10.1007/s11665-012-0433-7

[47] Brooks JW, Bridges PJ (1988) Metallurgical stability of Inconel Alloy 718. In: Reichman S, Duhl DN, Maurer G, Antolovich S, Lun C (eds) Superalloys, minerals, metals \& materials society, Champion, USA, 1988. pp 33-42. https://d oi.org/10.7449/1988/superalloys_1988_33_42

[48] Kuo CM, Yang YT, Bor HY, Wei CN, Tai CC (2009) Aging effects on the microstructure and creep behavior of Inconel 718 superalloy. Mater Sci Eng, A 510-511:289-294. http s://doi.org/10.1016/j.msea.2008.04.097

[49] Burger JL, Biederman RR, Gouts WH (1989) The effects of starting condition on the aging response of as-forged Alloy 718. In: Loria EA (ed) Superalloy 718-metallurgy applications, Pittsburgh, PA, USA, 1989, pp 207-217

[50] Zhang D, Feng Z, Wang C, Wang W, Liu Z, Niu W (2018) Comparison of microstructures and mechanical properties of Inconel 718 alloy processed by selective laser melting and casting. Mater Sci Eng A 724:357-367. https://doi.org/10. 1016/j.msea.2018.03.073

[51] You X, Tan Y, Shi S, Yang J-MM, Wang Y, Li J, You Q (2017) Effect of solution heat treatment on the precipitation behavior and strengthening mechanisms of electron beam smelted Inconel 718 superalloy. Mater Sci Eng A 689:257-268. https://doi.org/10.1016/j.msea.2017.01.093

[52] Schirra JJ, Viens DV (1994) Metallurgical factors affecting the machinability of Inconel 718. In: Loria EA (ed) Superalloys 718, 625, 706 Var. Deriv., The Minerals, Metals \& Materials Society, 1994, pp 827-838. https://doi.org/10.744 9/1994/superalloys 1994827838

[53] Keiser DD, Brown HL (1976) A review of the physical metallurgy of Alloy 718. Idaho National Engineering Laboratory, Idaho Falls

[54] Geng L, Na Y-S, Park N-K (1997) Continuous cooling transformation behavior of Alloy 718. Mater Lett 30:401-405. https://doi.org/10.1016/s0167-577x(96)00225-x 
[55] Cao J, Wang YF, Song XG, Li C, Feng JC (2014) Effects of post-weld heat treatment on microstructure and mechanical properties of TLP bonded Inconel718 superalloy. Mater Sci Eng A 590:1-6. https://doi.org/10.1016/j.msea.2013.10.013

[56] Fisk M, Andersson J, du Rietz R, Haas S, Hall S (2014) Precipitate evolution in the early stages of ageing in Inconel 718 investigated using small-angle x-ray scattering. Mater Sci Eng A 612:202-207. https://doi.org/10.1016/j.msea.201 4.06 .036

[57] Lee HJ, Kim HK, Hong HU, Lee BS (2019) Influence of the focus offset on the defects, microstructure, and mechanical properties of an Inconel 718 superalloy fabricated by electron beam additive manufacturing. J Alloys Compd 781:842-856. https://doi.org/10.1016/j.jallcom.2018.12.070
[58] ASTM E140-12b (2012) Standard hardness conversion tables for metals relationship among brinell hardness, vickers hardness, rockwell hardness, superficial hardness, knoop hardness, scleroscope hardness, and Leeb hardness. ASTM International 1-25. https://doi.org/10.1520/e0140-12b.1

[59] S.M. Corporation (2007) INCONEL ${ }^{\circledR}$ alloy 718. https:// www.specialmetals.com/assets/smc/documents/inconel_alloy_7 18.pdf. Accessed 23 Feb 2017

Publisher's Note Springer Nature remains neutral with regard to jurisdictional claims in published maps and institutional affiliations. 